\title{
Os dilemas das políticas de inclusão social
}

Rubens R. Sawaya

$\mathrm{P}$ ENSAR SAÍDAS e soluções para o desenvolvimento brasileiro é algo sempre bem-vindo, mesmo que, como não poderia deixar de ser em um livro de opiniões, as soluções estejam envoltas em discussões de fundo mais complexas.

O tema sobre o desenvolvimento econômico e social no Brasil é obviamente recorrente. As opiniões entre especialistas muitas vezes divergem, especialmente em razão da base teórica em que estão assentadas suas análises e suas posições políticas que resultam em propostas de ação específicas para combater a pobreza e a desigualdade. Interessantemente, este não é um livro que apresenta o aquecido debate que envolve o termo comum "reformas". Nem é essa sua proposta. Cada especialista convidado nos apresenta sua posição própria diante de seu diagnóstico. Deixam o debate para os leitores.

Esse conjunto de ensaios, publicados em 2007, parte de questões levantadas por um grupo de lideranças empresariais durante discussões para o Fórum Econômico Mundial de 2006 cujo foco estava na construção de condições para a "harmonização entre o crescimento econômico e a justa distribuição de seus proveitos", um problema recorrente na história do desenvolvimento brasileiro. Temos um histórico invejável de crescimento econômico (não mais para os chineses) com uma das piores distribuições de renda e benefícios sociais do mundo, o que nos leva a duvidar até mesmo da existência de democracia de fato e não apenas de direito no Brasil.

Os ensaios foram escritos com o objetivo de aprofundar e apresentar propostas de ação a determinados temas como educação, saúde, emprego, habitação, proteção social, infraestrutura, reforma tributária, inovação, comércio internacional e serviços financeiros. A pergunta central feita a cada especialista é o que deveria ser feito ou modificado para promover o desenvolvimento brasileiro com equidade.

O resultado, apesar de díspar, é bastante interessante, talvez por envolver autores com diferentes posições políticas e bases teóricas. As contradições aparecem apenas nas entrelinhas quando se tomam os artigos em conjunto, mas como os temas são diversos, não há embates explícitos. Há análises mais profundas e estruturais e outras mais superficiais baseadas em modelos internacionais a serem almejados, como transparece no texto "Eqüidade no acesso e cidades saudáveis".

$\mathrm{O}$ interessante no livro não se encontra tanto nos diagnósticos, nos quais as polêmicas são menores: há quase que um consenso quanto à necessidade de "reformas", apesar de esse termo carregar uma enorme generalização em sua base. A polêmica surge quase sempre quando as propostas se transformam em políticas para a ação e determinam o sentido dessas reformas, quando, aí sim, transparece sua ligação a interesses específicos.

Apenas como exemplo, o fato antes apontado se torna claro no artigo de Troster ao defender que a culpa dos enormes spreads bancários que elevam absurdamente as taxas de juros finais no Brasil é dos impostos cobrados sobre as operações de crédito, ou seja, do governo. Também aparece claramente no 
artigo de Zockum ao abordar o tema da reforma tributária a partir de determinados princípios que, embora internacionalmente consagrados por órgãos multilaterais como o Banco Mundial, carregam em si um viés teórico polêmico ao diminuir a capacidade de o Estado fazer política econômica fiscal e de interferir no mercado. Há uma visão política de Estado e mercado. Há, portanto, posições políticas no livro que tomam a aparência de simples proposições técnicas.

Outro exemplo disso aparece no fato de alguns autores trabalharem de partida com a hipótese subjacente de que não existem recursos para as políticas públicas, enquanto outros abordam o problema como uma questão de decisão política na alocação dos recursos existentes. $\mathrm{O}$ mesmo ocorre com a contradição entre focalização e universalização das políticas públicas, apesar de que, nesse caso, pende mais para a defesa da focalização, talvez à exceção dos textos de Pochmann sobre o mercado de trabalho, e de Haddad sobre a questão da educação.

É fundamental, porém, que se destaque: não há apenas um viés político no livro como um todo. Há uma importante e saudável diversidade de opiniões em cada texto isoladamente - como de fato não poderia deixar de ocorrer em qualquer trabalho que trate de "ação política" - que enriquece muito o resultado. Deve-se destacar que os textos abordam problemas extremamente importantes.

Tentou-se no livro dividir os problemas em três blocos, além da Introdução - Parte 1. A Parte 2 busca tratar dos problemas de infraestrutura (saneamento), habitação, inovação, fechando com uma proposta de organização para o desenvolvimento local. A Parte
3 trabalha as questões até certo ponto econômico-financeiras focadas no sistema tributário, crédito, proteção social e comércio internacional. A Parte 4 aborda as questões relacionadas ao trabalho e à educação. Certamente essa divisão não deve ter sido uma tarefa fácil, dado que os textos, muitas vezes, de um lado, se interpenetram e, de outro, apresentam, como apontado antes, algumas contradições entre si.

Abrindo o conjunto da obra, Marcovitch, o organizador do livro, enfatiza os problemas que imobilizam o Estado como o excesso de burocracia, a falta de continuidade das políticas em razão da troca de governantes e da forma de decisão política presente na relação entre governo e Parlamento. Esses seriam parte dos problemas que emperram as propostas de políticas públicas para o desenvolvimento. Impedem que as proposições dos especialistas se realizem concretamente no sentido de uma melhor distribuição dos benefícios econômicos na sociedade.

O problema do saneamento abre a Parte 2. Motta aponta que, apesar da sensível melhora no provimento desses serviços, o porcentual de coleta de esgoto ainda é muito baixo e a população pobre é a menos assistida. Isso ocorre mesmo com o fornecimento de água apesar do elevado porcentual de atendimento nesse segmento. Traz ao debate também a questão da eficiência da gestão empresarial no fornecimento dos serviços. Aponta que empresas com gestão local, no âmbito do município, tendem a ser mais eficientes, mas não esconde sua predileção pela administração privada. Segundo o autor, a solução seria elevar a participação privada no fornecimento dos serviços, dada sua maior 
eficiência. Em seu ponto de vista, o principal problema para avançar nesse sentido seria uma nova regulação que eleve a segurança jurídica do agente privado e, ao mesmo tempo, impeça abusos pelo fato de o setor ser um monopólio natural. Abordando a questão dos subsídios, explica que há distorções nesse quesito e defende uma melhor focalização nas classes mais pobres.

Maricato trabalha a questão da habitação no Capítulo 3. Aponta o tamanho do déficit habitacional considerando não apenas a falta de moradia, mas também a baixa qualidade das habitações sem provimento de infraestrutura básica (saneamento). Estima as quantidades e os valores necessários para suprir essas necessidades tanto para o período atual como para o futuro, diante do crescimento populacional. Destaca que o problema habitacional está concentrado na população de baixa renda e em cidade com população superior a cem mil habitantes. Resolver as condições de moradia tem impactos muito positivos não apenas para as pessoas diretamente envolvidas, mas para o país: de um lado, pelo efeito multiplicador que investimentos no setor acarretam para a economia; de outro, porque, ao melhorar as condições de vida da população, contribui para elevar a produtividade do trabalho.

Guilherme Plosnki aborda a questão da inovação sob a perspectiva do fomento à criatividade. Vê a inovação como o eixo estruturante do desenvolvimento nacional. Passa, ao longo de seu texto, por diversos programas e iniciativas que são, em sua opinião, importantes para a criação de um ambiente favorável à inovação. Para ele, a questão central é criar condições básicas para que a criatividade existente em cada indivíduo se transfor- me em inovação, colocando o país em um novo patamar de desenvolvimento. Ao lado disso, trabalha com a ideia de que é necessária a criação de programas nacionais de diversos tipos que carreiem essa criatividade para a inovação. Ressalta que esse ambiente é o resultado de uma ação conjunta entre governo, estrutura produtiva e infraestrutura científico-tecnológica.

Partindo da ideia de "cidades saudáveis", Westphal trabalha no Capítulo 5 a questão do desenvolvimento local. Tomando a ideia da eliminação de privações para a criação de oportunidades a partir de Amartya Sen, aponta estratégias para a melhoria das condições de vida e saúde das populações pelo acesso a serviços básicos. Baseado no "modelo sanitário Europeu", trabalha o conceito de cidade saudável no sentido de motivar governos e sociedade civil a desenvolver estratégias de criação e implementação de políticas sociais em âmbito local. Vê a cidade como uma estrutura social e comunitária específica, um lócus relativamente autônomo, cujo desenvolvimento econômico e social depende fundamentalmente da ação organizada de seus habitantes. Modelo interessante, embora às vezes pareça algo distante da verdadeira realidade social e política que caracteriza os pobres municípios brasileiros.

A Parte 3 do livro procura agrupar os artigos que tratam das condições econômico-financeiras para o desenvolvimento e reúne quatro artigos ligados a temas econômicos, dois deles talvez mais polêmicos: um que propõe a reforma tributária e outro que aborda a questão do crédito; o terceiro trata da questão dos mecanismos de proteção social e o último aborda os problemas da abertura comercial. 
Diante da questão tributária, Zockun traz uma proposta de reforma baseada em princípios consagrados pelos órgãos multilaterais que têm sido base para os projetos de diminuição do poder do Estado em intervir nos mercados. São eles os princípios que norteiam a arrecadação de impostos baseados em eficácia, neutralidade, equidade, competitividade e simplicidade. A partir disso, tece uma proposta de redução dos tributos para apenas dois: sobre o consumo e sobre a renda. O resultado seria eficiência com diminuição da carga tributária. Com isso, em sua opinião, seriam liberadas as amarras que impedem o crescimento econômico pelos elevados impostos, bem como as injustiças, subjacentes aos princípios. Retira o foco da política fiscal sobre a cobrança dos impostos e a transfere para o gasto focalizado aos mais necessitados. O objetivo é, assim, interferir o mínimo possível na "eficiência dos mercados".

Tratando do financiamento, o artigo de Troster apresenta a questão do custo do crédito como um problema de oferta e demanda de fundos disponíveis. Para ele, é da natureza do sistema competitivo que surge uma taxa de juros de equilíbrio, resultado natural dessa relação entre ofertantes e demandantes de recursos. Segundo sua visão, o que distorce essa taxa de juros "natural", especialmente para os pequenos empresários, são, de um lado, escala e risco, e de outro, a insegurança para os bancos diante das políticas macroeconômicas e do ambiente institucional (como a dificuldade jurídica para retomar créditos de inadimplentes). Mas destaca, acima de tudo, que as taxas de juros são elevadas no Brasil por culpa da elevada carga tributária. O problema todo está no ta- manho da dívida pública que não apenas faz que os bancos prefiram a segurança de emprestar ao governo, diminuindo a oferta de recursos, mas também é a responsável por essa carga. Assim, a culpa é do Estado, e não dos bancos. Para Troster, estes últimos agem segundo a lógica natural do mercado. Tal conclusão não poderia ser diferente para um representante do sistema bancário.

O Capítulo 8, de Barros \& Carvalho, trata a questão da proteção social tomando como elemento central a Bolsa-Família, vendo-a como positiva. A preocupação dos autores é como transformar essa política de renda mínima que beneficia as famílias mais pobres em algo que as ajude a sair da situação de pobreza extrema. Assim, sugerem formas de administrar o benefício, de modo a evitar que as famílias se acomodem na situação de assistidas e não busquem outras soluções. Propõem, então, um sistema de reciprocidade por parte das famílias atendidas com atividades que possam lhes possibilitar alternativas de sobrevivência sem a necessidade do programa.

Abordando a questão do comércio exterior, Ventura-Dias analisa os custos da liberalização comercial em termos de geração de emprego e renda no país. A pergunta que faz é clássica: a liberalização comercial de fato implica desenvolvimento com inclusão social? Sua análise dos fatos a leva a responder negativamente, apontando que não é um processo garantido nem automático. No caso brasileiro, a abertura comercial custou mais empregos do que gerou e beneficiou fundamentalmente as grandes empresas multinacionais. Os anos de liberalização comercial deram mais poder às grandes empresas na barganha entre trabalho e capital. Não beneficiou 


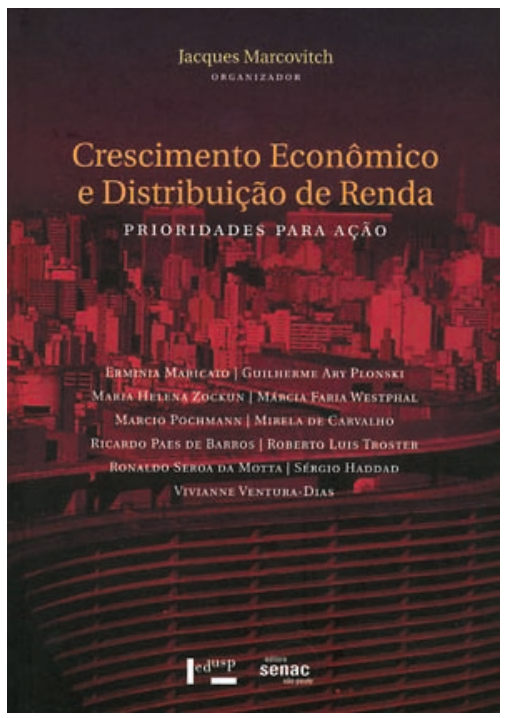

MARCOVITCH, Jacques (Org.) Crescimento econômico e distribuição de renda: prioridades para ação. São Paulo: Edusp, 2007. 232p.

a massa de trabalhadores menos qualificados em busca de emprego, tampouco as pequenas e médias empresas. Conclui afirmando que na ausência de políticas e estratégias específicas nada garante o benefício da abertura comercial. Contraria assim, de forma interessante, as teorias tradicionais tão difundidas nos últimos anos.

A Parte 4, a última do livro, traz dois artigos bastante interessantes. Um deles, de Pochmann, aponta a necessidade de pensar em uma nova forma de tratar a questão do desemprego no Brasil. Em seu diagnóstico, aponta os conhecidos elevados níveis de desemprego em razão, de um lado, da pressão exercida pelos novos ingressantes no mercado, incrementada pelo fato de que poucos trabalham muito por baixos salários; de outro, da baixa demanda por trabalhadores, dado o baixo crescimento econômico, situação agravada pela abertura comercial que cortou mais empregos do que os criou. Segundo ele, a solução para o desemprego não pode mais estar restrita à dicotomia entre emprego formal e informal. Uma nova regulação deve ser criada para abarcar as novas formas de emprego, recolocando a questão da formalização em outro patamar. A solução não seria, portanto, cortar direitos dos trabalhadores formais, mas, ao contrário, regulamentar e criar condições para ampliar os direitos aos trabalhadores no mercado que denomina "não-estruturado".

O último artigo, de Sérgio Haddad, trata da educação, apontando a precariedade do sistema envolvido em três problemas de fundo: a falta de vagas, a precariedade do ensino e a dificuldade em manter o aluno na escola. Muitas crianças se encontram fora da escola não apenas pela falta de vagas, mas pela condição de pobreza das famílias. Para aqueles jovens que têm vagas e conseguem permanecer na escola, o problema é a precariedade do aprendizado. Esses elementos afetam especialmente as famílias mais pobres em regiões menos assistidas. Segundo o autor, o Brasil gasta muito pouco com seus alunos. É, portanto, necessário não apenas reavaliar as questões levantadas no diagnóstico, mas elevar o gasto público por aluno.

As propostas reunidas no livro são muito bem-vindas, indo além do debate em que estão envolvidas. É interessante notar que foi a trajetória de crescimento econômico brasileiro, iniciada em 2003, que abriu esse leque de discussões entre os vários grupos de acadêmicos. Só então se passou a pensar em oportunidades e desafios para o Brasil no sentido de transformar esse crescimento em desenvolvimento. As questões são de extrema relevância diante da real situação social 
precária que se perpetua no Brasil e, com certeza, compromete seu próprio desenvolvimento.

Rubens R. Sawaya é doutor em Ciência Política, mestre em Economia Política, professor do Departamento de Economia da PUC-SP e vice-presidente da Sociedade Brasileira de Economia Política (SEP). É autor do livro Subordinação consentida: capital multinacional no processo de acumulação da América Latina e Brasil (Annablume, 2006).

@ - rsawaya@uol.com.br 